\title{
In-Sewer aerobic and anaerobic laboratory-scale degradation study of organic pollutants in sewage
}

\begin{abstract}
The course of the degradation of pollutants in terms of chemical oxygen demand (COD), soluble COD (SCOD), phenols, and anionic surfactants was examined both aerobically and anaerobically in sewer-like conditions. The rates of COD and SCOD degradation under aerobic condition were 0.051 and $0.052 \mathrm{mg} / \mathrm{L} / \mathrm{h}$, respectively. COD concentration remained unchanged during anaerobic process. However, SCOD was observed to increase with a production rate of $0.010 \mathrm{mg} / \mathrm{L} / \mathrm{h}$. The concentration of phenols was observed to decrease at a rate of $0.0211 / \mathrm{h}$ remained constant during the anaerobic process. The same profile was observed in the concentration of anionic surfactants, wherein the rate of degradation was $0.0454 / \mathrm{h}$ aerobically, and the concentration profile remained constant.
\end{abstract}

Keyword: In-sewer; COD; SCOD; Phenol; Anionic surfactants; Aerobic; Anaerobic; Degradation 